\title{
An User Friendly Tool to Assess the Effects on Agricultural Soils of Different Practices: The QBS-Ar Index
}

ISSN: 2637-7659

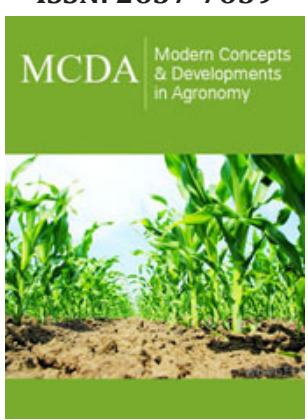

*Corresponding author: Loris Galli, Department of Earth, Environmental and Life Sciences (DISTAV), Genoa University, Corso Europa 26, I-16132 Genoa, Italy

Submission: 㘹June 25, 2020

Published: 些July 13, 2020

Volume 6 - Issue 5

How to cite this article: Loris Galli. An User Friendly Tool to Assess the Effects on Agricultural Soils of Different Practices: The QBS-Ar Index. Mod Concep Dev Agrono. 6(5). MCDA. 000648. 2020. DOI: 10.31031/MCDA.2020.06.000648

Copyright@ Loris Galli, This article is distributed under the terms of the Creative Commons Attribution 4.0 International License, which permits unrestricted use and redistribution provided that the original author and source are credited.

\section{Loris Galli*}

Department of Earth, Environmental and Life Sciences (DISTAV), Genoa University, Italy

\begin{abstract}
The QBS-ar index was proposed in Italy nearly 20 years ago as a biotic index aimed at biological quality assessment of soils based on their microarthropod communities composition and diversity. It is user friendly and quite expeditious. Therefore, since its introduction, it was applied in many natural and anthropogenic terrestrial environments in order to assess the impact of different forms of disturbance. QBSar resulted a reliable and sensitive tool for environmental monitoring in most of the contexts in which it was used. In particular, in a wide range of crops (like maize, apple, citrus, vineyards) it proved to be an useful index to distinguish among different management practices (conventional, no tillage, organic, green manure, etc.). In this paper, the principles on which the QBS-ar index is based are summarized and some examples from literature on its application in agroecosystems are reviewed.
\end{abstract}

Keywords: Soil microarthropods; Agricultural lands; Management; Biological quality; Sustainability

\section{Introduction}

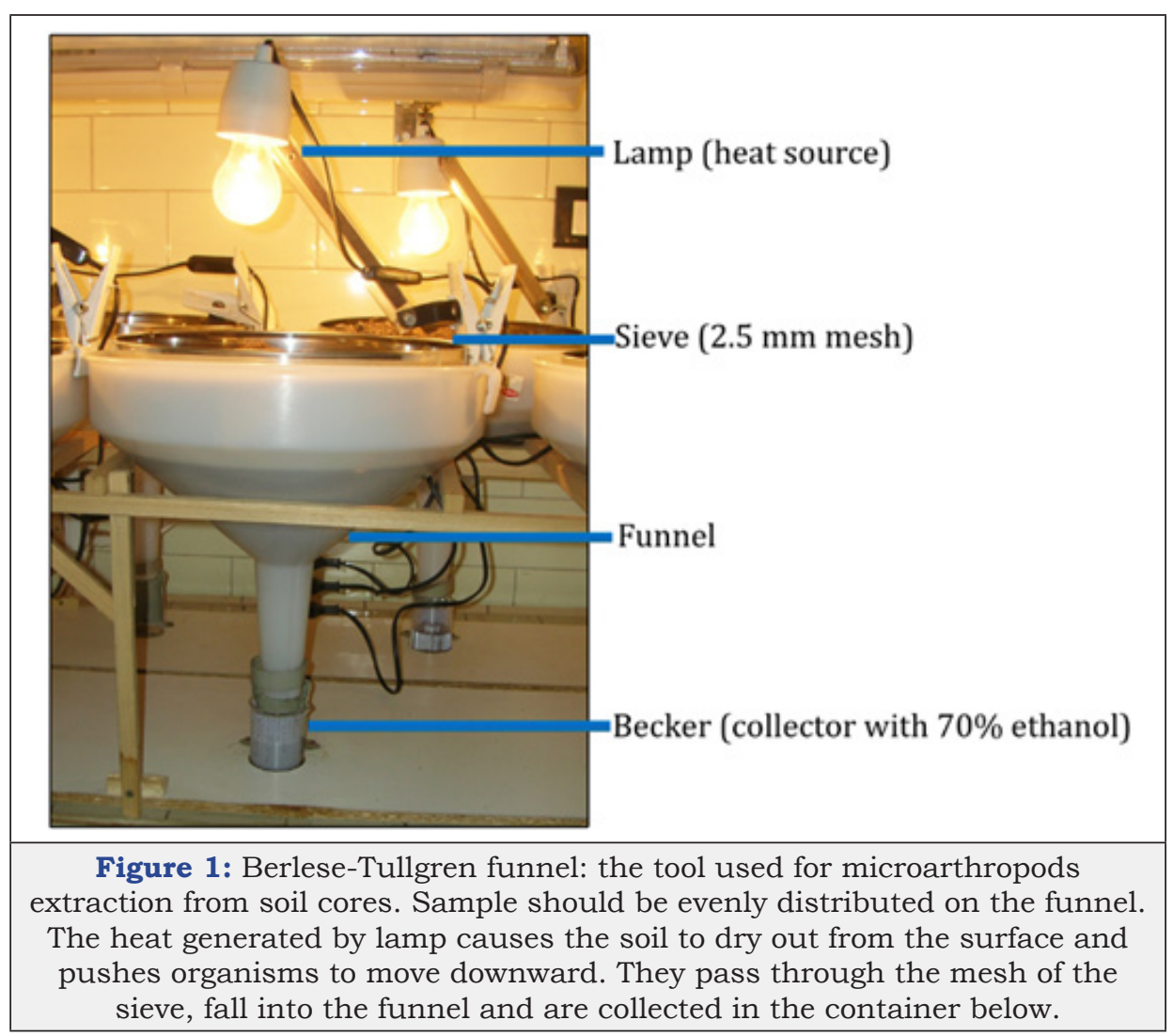

Soil Arthropods have often been used as soil quality indicators and to implement biotic indices [1]. Among the others, the QBS-ar index (Biological Quality of Soil, based on arthropods) 
[2] was introduced nearly 20 years ago for the estimation of the environmental quality in terrestrial habitats. This index is based on the correlation between the number of microarthropod groups adapted to soil habitats and the soil quality. Their extraction takes place by means of Berlese-Tullgren funnels (Figure 1). Each taxon is evaluated based on morphological characteristics that represent an adaptation to soil life (reduction or loss of pigmentation and eyes, tiny size or streamlined body, reduction and transformation of appendages, presence of peculiar sense organs). Based on these features, an eco-morphological index (EMI) ranging from 1 (no adaptation to soil) to 20 (full adaptation), is given to each arthropod order. The sum of EMI scores of all the groups extracted from a soil gives the QBS-ar value. The higher the value obtained, the better the biological quality of the soil examined. This index is low cost and easy to perform: field soil cores collection is expeditious and laboratory analyses require generic taxonomic skills. Therefore, since its introduction and improvement, the QBS-ar index was widely applied mainly in Italy and in other European countries, but also elsewhere. In particular, it was used both in order to evaluate soil quality in agroecosystems and in polluted or degraded sites, and to assess the impact of different disturbances in natural and semi-natural habitats [3].

\section{Discussion}

Some studies based on QBS-ar index considered agricultural lands as examples of degraded habitats in comparison to natural environments [4,5]. However, the literature does not lack cases in which agroecosystems are the focus of investigation and different methods of agricultural management are compared. In chronological order, the QBS-ar index was successfully used in South Italy to distinguish citrus groves subjected to plowing and grassing, with values of 65 and 132, respectively [6]. This result reflects the negative effect of mechanical disturbances on soil arthropods communities. On the contrary, in Lombardy (NWItaly) such index resulted sensitive enough to detect the important seasonal variations in soil conditions but not able to express a clear gradient of biological soil quality among three investigated sites differing for agronomic practices, but also in terms of agronomic history and soil characteristics [7]. Similarly, the QBS-ar index did not show significant differences among barley monoculture fields under different soil management systems (conventional tillage, no-tillage and nitrogen fertilization) [8]. The same results were obtained analyzing maize fields: the index turned out to be unsuitable for detecting the influence of tillage management and $\mathrm{N}$ fertilization on the microarthropod community [9].

The suitability of the method, on the other hand, was positively tested in Northern Italian corn crops, where reference values of the QBS-ar index $(76.4 \pm 23.5)$ for such environment were recorded [10]. A multidisciplinary approach in conventional and organic stockless arable systems highlighted the responses of biological quality index to different forms of management and disturbance
[11]. The same is true for a 15 year study carried out in Central Italy, where mean QBS-ar value (75) resulted higher in no-tillage crops than in conventional tillage (43.3) [12]. A sensitivity to different maize farming systems, with a maximum of 183 in fields converted to organic management for six years, was outlined too [13]. Organic management led to higher quality scores (mean QBS-ar values over 150) than conventional management (mean 120) in sites under different cultivations (apple, kiwi, vineyards, strawberry, asparagus) [14]. Moreover, an extensive research in South Tyrol [15] highlighted that QBS-ar reacts sensitively to land use and can serve as an important indicator for sustainable land use practices. Mean values ranging from 95-98 in anthropogenic habitats like arable fields and mountain pastures, to 175 in undisturbed mixed deciduous forest were obtained. In the Valpolicella area (Veneto), the index made it possible to differentiate, according to an increasing biological quality gradient, conventional vineyards (QBS-ar=92), organic green manure vineyards (QBS-ar=102) and classic organic vineyards (not subject to plowing disturbance characterizing green manure - QBS-ar=141) [16]. The reliability of this tool to discriminate soil management practices in vineyards was highlighted also in Piedmont [17] and Northeast Portugal [18]. In the former case it was recorded an increasing QBS-ar value from conventional (109), through integrated and organic, to biodynamic management practices (143). In the latter, the QBS-ar index was significantly higher in ground cover treatments (80) than in the tillage (48). Finally, it is worth remembering that, based on the same principle and approach of the QBS-ar index, some more specialized indices were suggested too. The QBS-C, is based only on the Collembolan community and it proved to be highly effective in the evaluation of differences in soils characterized by different organic matter content, moisture and mechanical tillage [19]. More recently, the QBS-e, based on earthworms, was designed for farmers and operators with limited expertise on species taxonomy [20].

\section{Conclusion}

Although with some exceptions, the QBS-ar index, after almost 20 years from its introduction, turned out to be a reliable and sensitive tool for environmental monitoring in agroecosystems. A 15 years review on this method confirmed that land use significantly affects QBS-ar values and that a value of 93.7 can be considered a threshold separating high quality soils from poor soils [3]. Thanks to its ease of execution, this index can be applied by operators without particularly in-depth taxonomic skills, providing in a short time a numerical output of easy interpretation. Therefore, its application is recommended whenever the responsible of agricultural lands wish to assess the effects of different practices or to face a more sustainable management.

\section{Conflict of Interest}

The author declare that the research was conducted in the absence of any commercial or financial relationships that could be construed as a potential conflict of interest. 


\section{References}

1. Menta C, Ramelli S (2020) Soil health and arthropods: from complex system to worthwhile investigation. Insects 11(1): 54.

2. Parisi V, Menta C, Gardi C, Jacomini C, Mozzanica E (2005) Microarthropod communities as a tool to assess soil quality and biodiversity: A new approach in Italy. Agric Ecosyst Environ 105(1-2): 323-333.

3. Menta C, Conti FD, Pinto S, Bodini A (2018) Soil Biological Quality index (QBS-ar): 15 years of application at global scale. Ecol Indic 85: 773-780.

4. Menta C, Leoni A, Gardi C, Conti FD (2011) Are grasslands important habitats for soil microarthropod conservation? Biodivers Conserv 20: 1073-1087.

5. Menta C, Conti FD, Pinto S (2018) Microarthropods biodiversity in natural, seminatural and cultivated soils-QBS-ar approach. Appl Soil Ecol 123: 740-743.

6. Talarico F, Romeo M, Mazzei A, Brandmayr Zetto T, Brandmayr P (2006) Valutazione della qualità biologica del suolo (QBS) in un agrumeto della provincia di Vibo Valentia. $16^{\text {th }}$ Meeting of the Italian Society of Ecology, Italy.

7. Gardi C, Menta C, Leoni A (2008) Evaluation of the environmental impact of agricultural management practices using soil microarthropods. Fresenius Environ Bull 17(8): 1165-1169.

8. Tabaglio V, Gavazzi C, Menta C (2008) The influence of no-till, conventional tillage and nitrogen fertilization on physico-chemical and biological indicators after three years of monoculture barley. Ital J Agron 3(4): 233-240.

9. Tabaglio V, Gavazzi C, Menta C (2009) Physico-chemical indicators and microarthropod communities as influenced by no-till, conventional tillage and nitrogen fertilisation after four years of continuous maize. Soil Till Res 105(1): 135-142.

10. Aspetti GP, Boccelli R, Ampollini D, Del Re AAM, Capri E (2010) Assessment of soil-quality index based on microarthropods in corn cultivation in Northern Italy. Ecol Indic 10(2): 129-135.
11. Mazzoncini M, Canali S, Giovannetti M, Castagnoli M, Tittarelli F, et al. (2010) Comparison of organic and conventional stockless arable systems: a multidisciplinary approach to soil quality evaluation. Appl Soil Ecol 44(2): 124-132.

12. Sapkota TB, Mazzoncini M, Bàrberi P, Antichi D, Silvestri N (2012) Fifteen years of no till increase soil organic matter, microbial biomass and arthropod diversity in cover crop-based arable cropping systems. Agron Sustain Dev 32: 853-863.

13. Simoni S, Nannelli R, Castagnoli M, Goggioli D, Moschini V, et al. (2013) Abundance and biodiversity of soil arthropods in one conventional and two organic fields of maize in stockless arable systems. Redia 96: 37-44.

14. Menta C, Tagliapietra A, Caoduro G, Zanetti A, Pinto S (2015) Ibs-Bf and Qbs-Ar comparison: two quantitative indices based on soil fauna community. EC Agriculture 2.5: 427-439.

15. Rüdisser J, Tasser E, Peham T, Meyer E, Tappeiner U (2015) The dark side of biodiversity: spatial application of the biological soil quality indicator (BSQ). Ecol Indic 53: 240-246.

16. Linnyk V, Latella L, Zanella A (2019) La gestione agronomica influenza la microfauna del suolo in vigneto. Vite \& Vino 4: 34-38.

17. Simoni S, Guidi S, Vignozzi N, Valboa G, Goggioli D, et al. (2019) Functional diversity of edaphic microarthropods for snapshot soil quality assessment in Barbera vineyards. Landscape management for functional biodiversity IOBC-WPRS Bulletin 143: 31-35.

18. Gonçalves F, Nunes C, Carlos C, López Á, Oliveira I, et al. (2020) Do soil management practices affect the activity density, diversity, and stability of soil arthropods in vineyards? Agr Ecosyst Environ 294: 106863.

19. Parisi V, Menta C (2008) Microarthropods of the soil: convergence phenomena and evaluation of soil quality using QBS-ar and QBS-C. Fresenius Environ Bull 17: 1170-1174.

20. Paoletti MG, Sommaggio D, Fusaro S (2013) Proposta di indice di Qualità Biologica del Suolo (QBS-e) basato sui lombrichi e applicato agli agroecosistemi. Biologia Ambientale 27(2): 25-43. 